\title{
RP-HPLC Method for the Determination of Cinitapride in the Presence of its Degradation Products in Bulk Drug
}

\author{
S.M.N.ROY*, KIRAN V. MANGAONKAR, \\ A.Y. DESAI and SANTOSH M. YETAL \\ Mithibai College of Art, Chawhan Institute of Science, \\ Amrutben Jivanlal College of Commerce and Economics, \\ Vileparle(West), Mumbai- 400056, India. \\ shikhamonish@gmail.com
}

Received 28 March 2009; Accepted 13 May 2009

\begin{abstract}
A reverse phase HPLC method is described for the determination of cinitapride hydrogen tartrate in the presence of its degradation products in bulk drug. A drug was subjected to all stress conditions such as reduction, oxidation acidic and alkaline medium. Chromatography was recorded on an Intersil ODS-3 column using mixture of acetonitrile and phosphate buffer, $\mathrm{pH}$ adjusted to 6.7 in the ratio $(70: 30 \mathrm{v} / \mathrm{v})$ as the mobile phase at the rate of $1.0 \mathrm{~mL} / \mathrm{min}$ with detection at $260 \mathrm{~nm}$. Glimepride was used as internal standard. The retention time of drug cinitapride was $3.8 \mathrm{~min}$ and glimepride an internal standard was 2.5 minute. The drug was found to degrade extensively in reduction conditions and mild degradation in the presence of in alkaline, acidic and oxidative but the drug was stable in thermal stress. The method was validated by determining its specificity, linearity, precision and accuracy. The developed method with good separation of all degradation products from drug could be successfully applied for the determination of cinitapride in the presence of its degradation products in the bulk drug. The proposed method is simple, fast, accurate and precise and hence applied for routine quality control of cinitapride in bulk drug. It can be used for analysis of samples during stability testing.
\end{abstract}

Keywords: RP-HPLC, Cinitapride, Determination of cinitapride, Degradation products.

\section{Introduction}

Cinitapride, chemically 4-amino- $N$-[3-(cyclohexan-1-yl-methyl)-4-piperidinyl]-2-ethoxy-5nitrobenzamide has the molecular formula $\mathrm{C}_{21} \mathrm{H}_{30} \mathrm{~N}_{4} \mathrm{O}_{4}$ and molecular weight 402.49 g.mol ${ }^{-1}$. Cinitapride is a drug that has against action to the serotoninergic 5-HT2 and D2 dopaminergic receptors that has been indicated in the gastroesophageal reflux and in the 
functional disorders of gastrointestinal motility treatment. The therapeutic effect of cinitapride lies on the capacity of increasing lower esophageal sphincter tone and has strong gastrokinetic activity, which generates significant increases in the gastric emptiness; besides, through the serotoninergic system it stimulates the intestinal activity. The use of cinitapride is efficient and safe in treatment of patients with disorders in the gastric emptiness related to gastroesophageal reflux and functional dyspepsia as well as in individuals that present irritable bowel syndrome with constipation and abdominal pain $^{1-3}$.The ICH guideline Q1A (R2) emphasizes that the testing of those features which are susceptible to change during storage and are likely to influence quality, safety and efficacy, must be done by validated stability indicating testing method. As per Q1 (R2) information on the stability of the drug substance is an integral part of the systematic approach to stability evaluation. Stress testing of the drug substance can help identify the likely degradation products, which can in turn help establish the degradation pathways and the intrinsic stability of the molecule and validate the stability indicating power of the analytical procedures used. The nature of the stress testing will depend on the individual drug substance and the type of drug product involved. Stress testing is likely to be carried out on a single substance. The main objective was to develop a suitable method of analysis which is stability indicating and to get an idea of how drug substance or product degrades, degenerates and behaves under changing conditions. By keeping all this in view, it was thorough worthwhile to develop stability indicating HPLC method. Literature survey reveals some chromatographic method has been used for determination by polarographic and in biological fluid by LC-MS/MS ${ }^{4-6}$. Since, article on method has not been reported for the estimation of Cinitapride as bulk drug. The present paper aims at reporting an isocratic RPHPLC method for the estimation of Cinitapride as bulk drug.

\section{Experimental}<smiles>CCOc1cc([N+](=O)[O-])c([N+](=O)[O-])cc1C(=O)NC1CCN(CC2CC=CCC2)CC1</smiles>

Working standard of cinitapride hydrogen tartrate and glimepride was obtained from Cadila healthcare Limited, Ankleshwar, India. Acetonitrile of HPLC grade were used of J.T. Baker Potassium dihydrogen phosphate and tri ethylamine of AR grade were obtained from Merck.

\section{Instrumentation and chromatographic conditions}

High performance liquid chromatography, Water Alliance separation module 2695, equipped with auto sampler injector, ultra-violet detector Water 2487 with Empower software. Chromatographic separation was achieved using Intersil ODS-3 column (150 mm x $4.6 \mathrm{~mm}, 3 \mu \mathrm{m})$ analytical column. The mobile phase consisting of acetonitrile and $0.1 \mathrm{M}$ potassium dihydrogen phosphate buffer, $\mathrm{pH}$ adjusted to 6.7 with triethylamine in the ratio $(70: 30 \mathrm{v} / \mathrm{v})$. The flow rate was maintained at $1.0 \mathrm{~mL} / \mathrm{min}$ and the measurement were made at $260 \mathrm{~nm}$. The column and auto sampler were kept at ambient temperature.

\section{Preparation of standard stock solution}

The stock solution of cinitapride $(100 \mu \mathrm{g} / \mathrm{mL})$ was prepared by dissolving $13.80 \mathrm{mg}$ cinitapride hydrogen tartrate sample $(99.7 \%)$ which is equivalent to $10.00 \mathrm{mg}$ cinitapride with mobile phase in a standard $100 \mathrm{~mL}$ volumetric flask. The stock solution of glimepride $(100.0 \mu \mathrm{g} / \mathrm{mL})$ was prepared by dissolving $10.01 \mathrm{mg}$ of glimepride as internal standard $(99.5 \%)$ with mobile phase in a standard $100 \mathrm{~mL}$ volumetric flask. 


\section{Preparation of sample solution}

Accurately weighed cinitapride hydrogen tartrate sample, which is equivalent to $10.00 \mathrm{mg}$ of cinitapride with mobile phase was dissolved in a standard $100 \mathrm{~mL}$ volumetric flask. Further $3.0 \mathrm{~mL}$ of cinitapride drug and $5.0 \mathrm{~mL}$ of internal standard $(100 \mu \mathrm{g} / \mathrm{mL})$ with mobile phase was diluted in a standard $10.0 \mathrm{~mL}$ volumetric flask.

\section{Forced degradation studies (stress testing)}

The drug concentration for all stress studies was taken $1 \mathrm{mg} / \mathrm{mL}$ as per standard literature. The bulk drug was subjected to alkaline studies by adding $1.0 \mathrm{~mL}$ of the $1 \mathrm{~N} \mathrm{NaOH}$ for 12 hours and neutralized with $1.0 \mathrm{~mL}$ of $1 \mathrm{~N} \mathrm{HCl}$ acid. Similarly, the acidic studies was performed by adding $1.0 \mathrm{~mL}$ of $1 \mathrm{~N} \mathrm{HCl}$ for 12 hours and neutralized with $1.0 \mathrm{~mL}$ of $1 \mathrm{~N} \mathrm{NaOH}$. Oxidation studies was performed on bulk drug by adding $1.0 \mathrm{~mL}$ of $5 \% \mathrm{H}_{2} \mathrm{O}_{2}$ for 12 hours and reduction studied was performed on bulk drug by adding $1.0 \mathrm{~mL} 1 \%$ sodium borohydrate for 12 hours. Bulk drug was subjected to heat at $80^{\circ} \mathrm{C}$ for 12 hours. All samples were taken in different $10 \mathrm{~mL}$ volumetric flasks and dissolved in mobile phase. Final assay drug concentration and external internal standard was made up with mobile phase and injected in the chromatographic system. All stressed sample were analyzed by developed HPLC method ${ }^{7-13}$.

\section{Method validation}

Validation of developed analytical method was performed as per ICH guideline Q2 B, over the linearity, accuracy, precision, specificity, limit of detection, limit of quantitation ${ }^{7-13}$.

\section{Results and Discussion}

Analysis of stressed samples

The ICH stability guideline Q1A (R2) defines stress testing for new drug substances and drug products, to elucidate the intrinsic stability of the drug substances and drug products. The stress testing may also provide information about degradation pathways and selectivity of the applied analytical method. The drug was found to degrade extensively on reduction (Figure 2) and in acidic medium $1 \mathrm{~N} \mathrm{HCl}$.(Figure 3). Mild degradation was observed, when exposed to oxidation (Figure 1), basic (Figure 4) and thermal condition (Figure 5). Degradation \% assay value given in Table 1 .

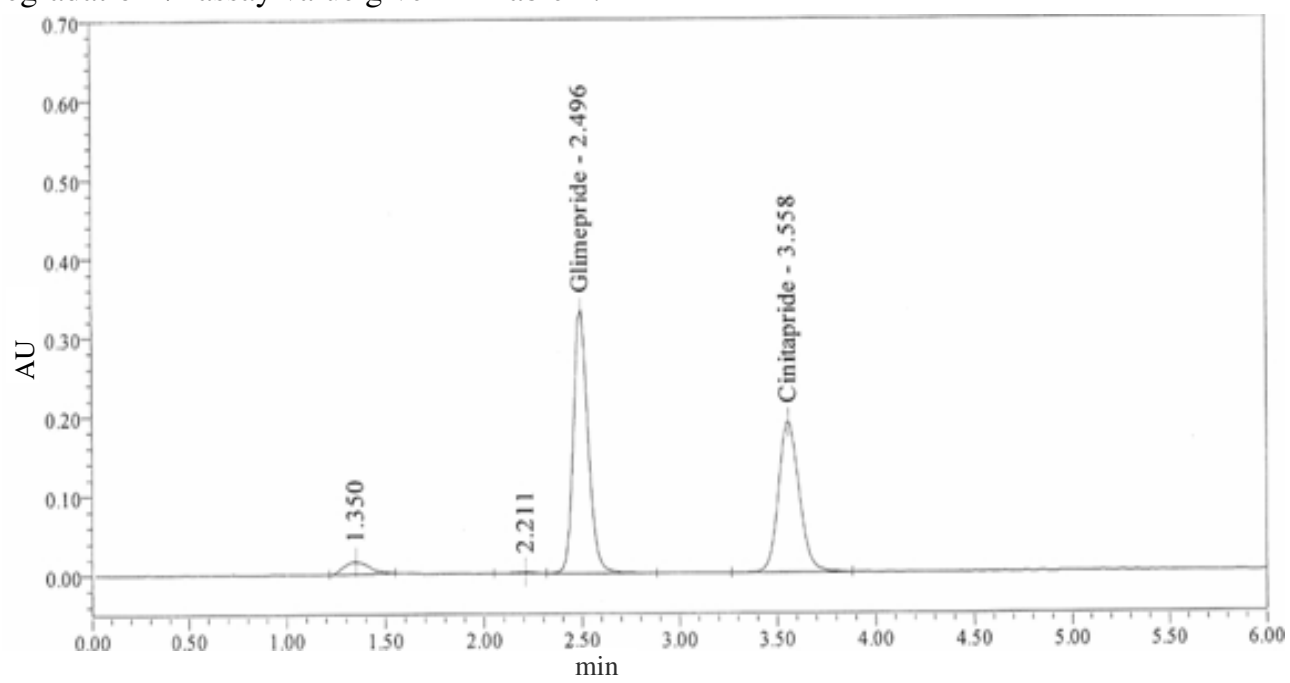

Figure 1. HPLC Chromatogram representing degradation behavior of cinitapride in oxidation. 


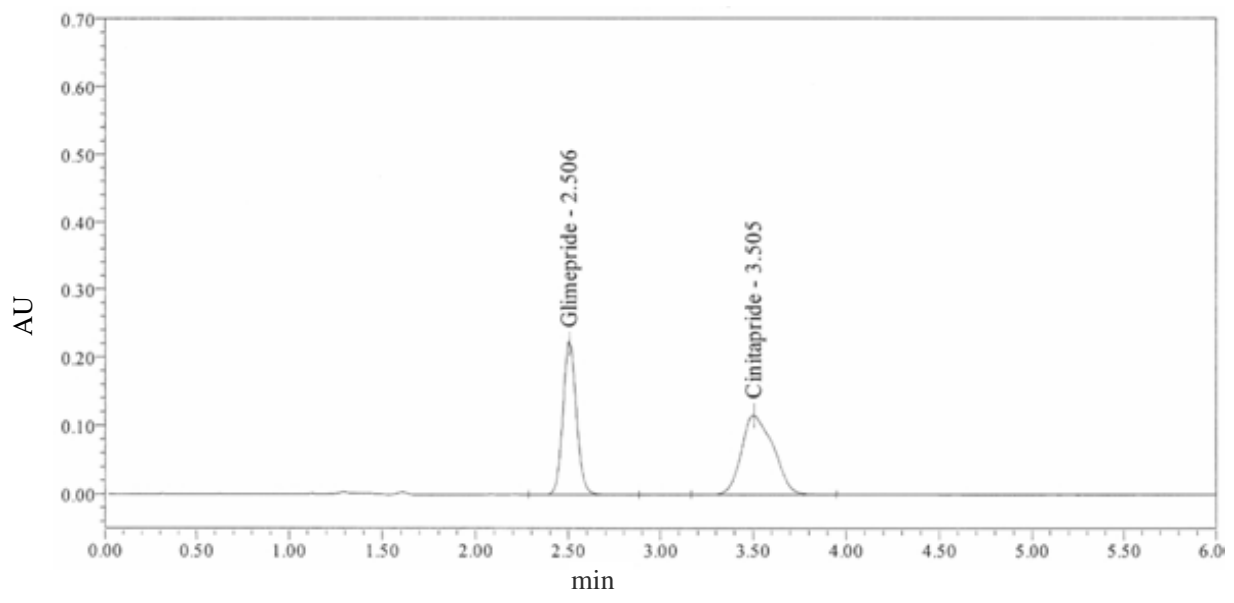

Figure 2. HPLC Chromatogram representing degradation behavior of cinitapride in reduction.

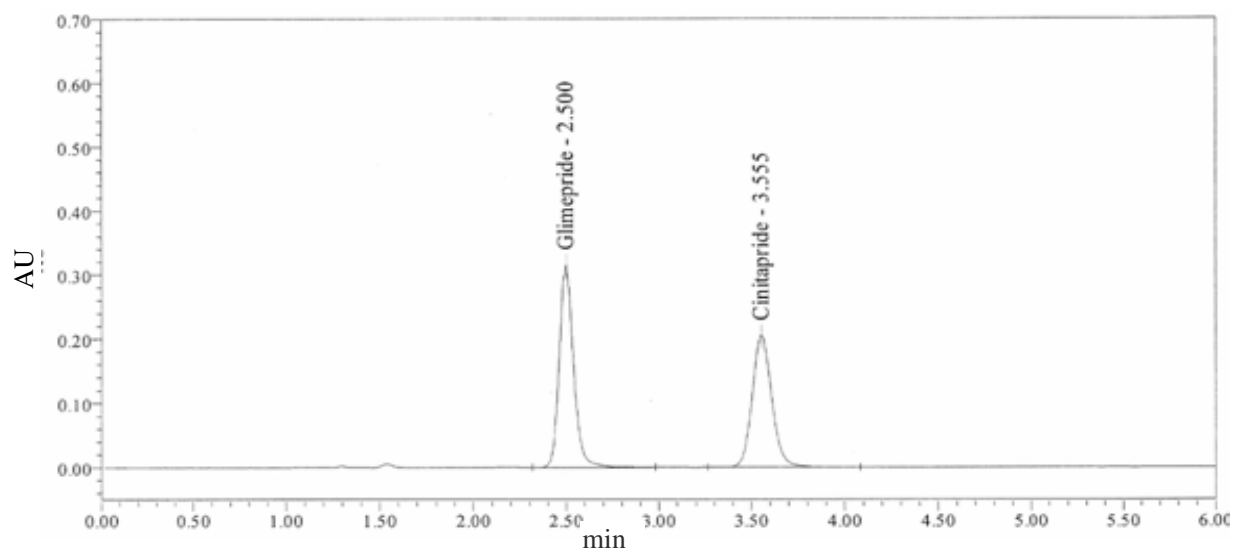

Figure 3. HPLC Chromatogram representing degradation behavior of cinitapride in acid.

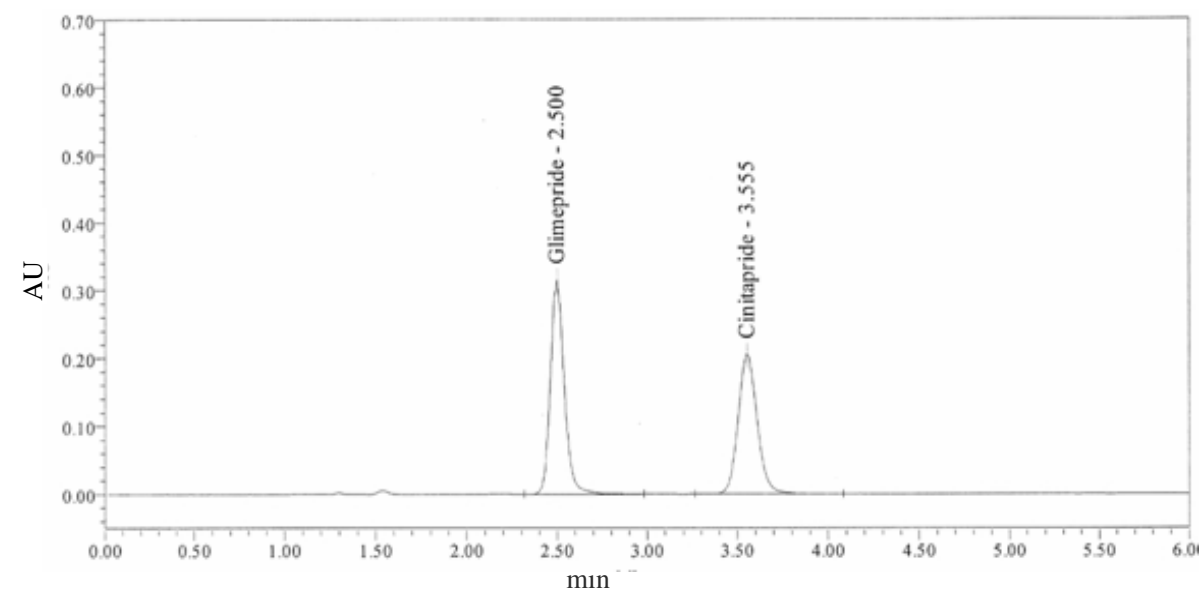

Figure 4. HPLC Chromatogram representing degradation behavior of cinitapride in base. 


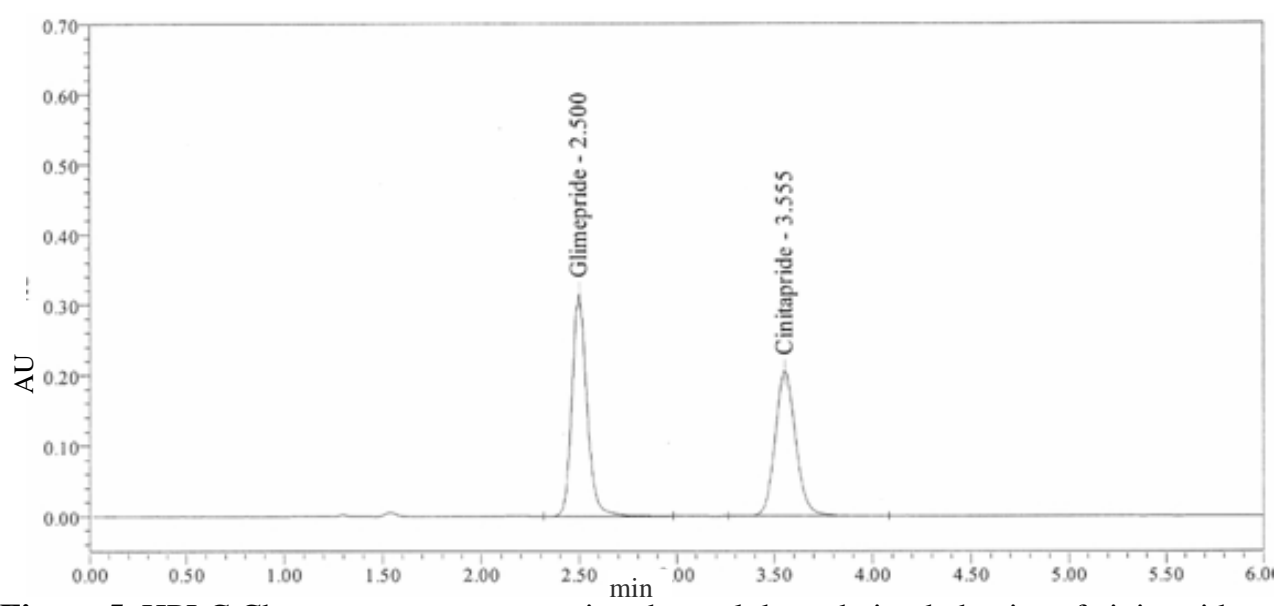

Figure 5. HPLC Chromatogram representing thermal degradation behavior of cinitapride.

Table 1. Degradation \% assay value.

\begin{tabular}{cccc}
\hline $\begin{array}{c}\text { Stress } \\
\text { conditions }\end{array}$ & $\begin{array}{c}\text { \% assay of drug after } \\
\text { exposed to stress } \\
\text { condition }\end{array}$ & $\begin{array}{c}\text { \% of degradation } \\
\text { impurity observed }\end{array}$ & $\begin{array}{c}\% \text { assay (impurity } \\
\text { observed+\% assay } \\
\text { after exposed }\end{array}$ \\
\hline Acidic-12 h & 95.2 & 5.5 & 100.7 \\
Basic-12 h & 96.2 & 4.4 & 100.7 \\
Oxidation-12 h & 99.6 & 1.0 & 100.7 \\
Reduction-12 h & 92.1 & 8.6 & 100.7 \\
Thermal -12 h & 99.3 & 1.3 & 100.7 \\
\hline
\end{tabular}

\section{Linearity}

Several aliquots of standard stock solution $(1.25,1.5,2.4,3.0,3.6$, and $4.5 \mathrm{~mL} ; 1 \mathrm{~mL}=100$ $\mu \mathrm{g} \mathrm{mL}{ }^{-1}$ ) of cinitapride drug and $5.0 \mathrm{~mL}$ glimepride internal standard were taken in different six standard $10.0 \mathrm{~mL}$ volumetric flasks and diluted up to mark with mobile phase. Evaluation was performed with UV detector at $260 \mathrm{~nm}$. The peak area was recorded for all the peaks and calibration graph was obtained by plotting peak area ratio versus concentration of cinitapride. The plot of peak area ratio against concentration of cinitapride was found to be linear in the range of 12.5 to $45 \mu \mathrm{g} / \mathrm{mL}$ with correlation coefficient of 0.9978.The respective slope, intercept and correlation coefficient given in Table 2.

\section{Limit of detection (LOD) and limit of quantitation (LOQ)}

LOD and LOQ were determined from standard deviation and slope method as per ICH guideline, for cinitapride LOD was found to be $2.841 \mu \mathrm{g} / \mathrm{mL}$ and LOQ was found to be $8.610 \mu \mathrm{g} / \mathrm{mL}$. The respective limit of detection, limit of quantitation and LOQ level precision is given in Table 3.

\section{Accuracy}

To study accuracy of the method, recovery experiment was carried out by spiked concentrations. A known quantity of drug substance corresponding to 80,100 and $120 \%$ was spiked, to determine accuracy (recovery) against $100 \%$ working standard. The accuracy was expressed as the percentage of analytes recovered by the assay. The results indicate the method is highly accurate for determination of the cinitapride. Table 4 lists the recoveries of the drugs from a series of spiked concentrations. 
Table 2. The calibration graph peak area ratio, slope, intercept and correlation coefficient.

\begin{tabular}{cccc}
\hline \multirow{2}{*}{$\begin{array}{c}\text { Concentration in } \\
\mu \mathrm{g} / \mathrm{mL}\end{array}$} & \multicolumn{2}{c}{ Area } & \multirow{2}{*}{ Area ratio } \\
\cline { 2 - 3 } & Cinitapride & Glimepride & \\
\hline 12.55 & 738395 & 993241 & 0.743 \\
15.06 & 884819 & 995672 & 0.889 \\
24.1 & 1192660 & 999956 & 1.193 \\
30.12 & 1489744 & 994231 & 1.498 \\
36.14 & 1770422 & 997862 & 1.774 \\
45.18 & 2208769 & 992456 & 2.226 \\
Correlation coefficient & & & 0.9978 \\
Slope & & & 0.0446 \\
Intercept & & & 0.1741 \\
\hline
\end{tabular}

Table 3. Results of LOD and LOQ.

\begin{tabular}{lc}
\hline Concentration in $\mu \mathrm{g} / \mathrm{mL}$ & Area \\
\hline 12.55 & 738395 \\
15.06 & 884819 \\
24.10 & 1192660 \\
30.12 & 1489744 \\
36.14 & 1770422 \\
45.18 & 2208769 \\
Correlation & 0.9981 \\
Slope & 44302.352 \\
SD & 38146.214 \\
LOD & 2.841 \\
LOQ & 8.610 \\
\% RSD for LOQ level & 4.52 \\
\hline
\end{tabular}

Table 4. Results of the study accuracy.

\begin{tabular}{ccccccc}
\hline $\begin{array}{c}\text { Level } \\
\%\end{array}$ & $\begin{array}{c}\text { Spiked conc., } \\
\text { ppm }\end{array}$ & $\begin{array}{c}\text { Recovered } \\
\text { conc., } p \text { pm }\end{array}$ & \% Recovery & Mean & S.D. & $\begin{array}{c}\% \\
\text { RSD }\end{array}$ \\
\hline \multirow{2}{*}{80} & 24.10 & 24.39 & 101.21 & & & \\
& & 24.32 & 100.92 & 101.21 & 0.29 & 0.29 \\
& & 24.46 & 101.51 & & & \\
100 & 30.12 & 30.68 & 101.86 & & & \\
& & 29.83 & 99.04 & 101.08 & 1.78 & 1.76 \\
& & 30.82 & 102.33 & & & \\
120 & 36.14 & 36.62 & 101.31 & & & \multirow{2}{*}{0.81} \\
& & 36.05 & 99.75 & 100.66 & 0.81 & 0.80 \\
\hline
\end{tabular}

\section{Precision}

Repeatability was studied by carrying out system precision and method precision. System precision was determined from results for six replicate injections of the system suitability standard solutions. The relative standard deviations were less than $2 \%$. Method precision was determined by estimated the percentage assay of Cinitapride. The relative standard deviation was 0.83.Refer Table 5. 
Table 5. Results of the study of relative standard deviation.

\section{Specificity}

\begin{tabular}{cc}
\hline S.No. & \% Assay \\
\hline 1 & 100.29 \\
2 & 101.72 \\
3 & 101.63 \\
4 & 99.84 \\
5 & 100.55 \\
6 & 99.88 \\
Mean & 100.65 \\
SD & 0.83 \\
\%RSD & 0.83 \\
\hline
\end{tabular}

Specificity is the ability to assess unequivocally the analytic in the presence of components that may be expected to be present. Typically, these might include impurities, degradedness, etc. injected individually and combined mixture of cinitapride and glimepride as internal standard (Figure 6-8). The method was said to be specific, there should not any interference at retention time of cinitapride and glimepride as internal standard in blank mobile phase solution.

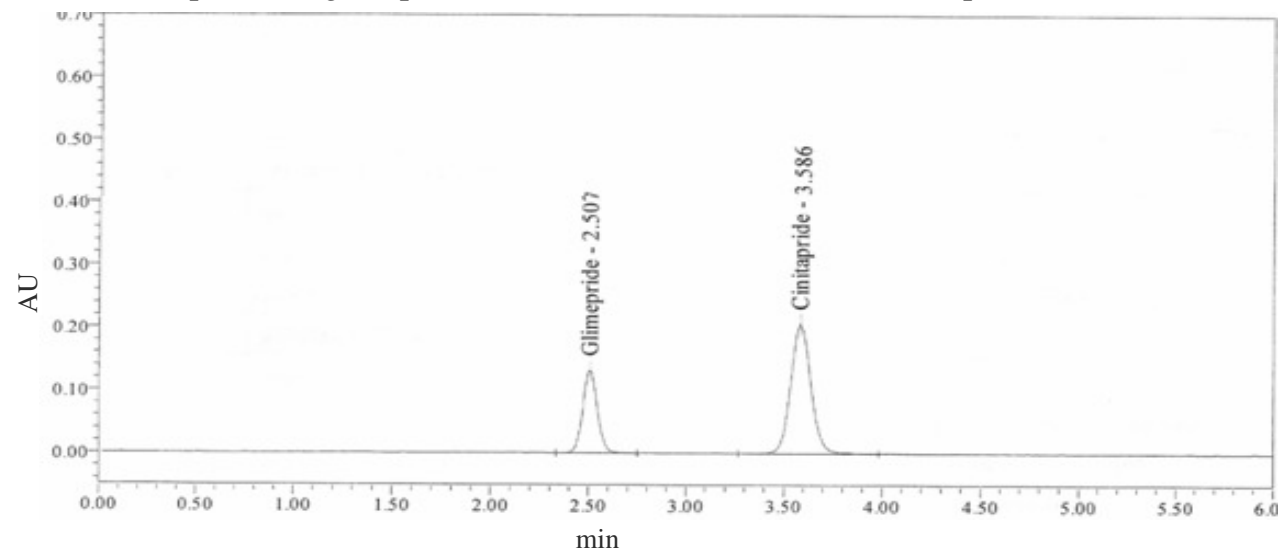

Figure 6. Specificity chromatogram of cinitapride and glimepride (Internal standard).

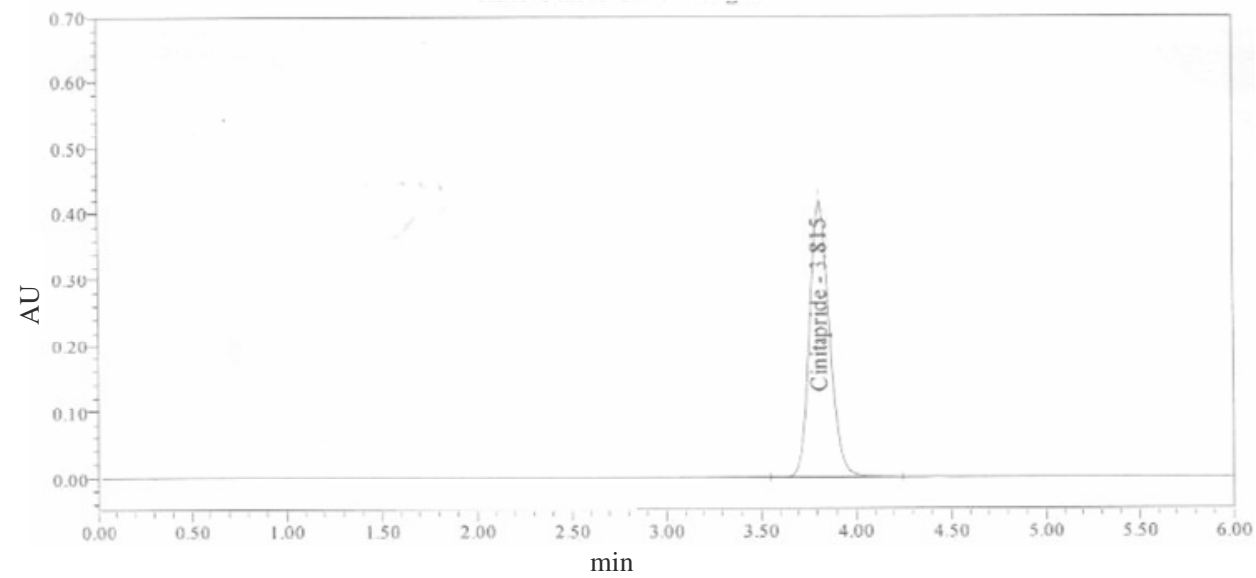

Figure 7. Specificity chromatogram of cinitapride. 


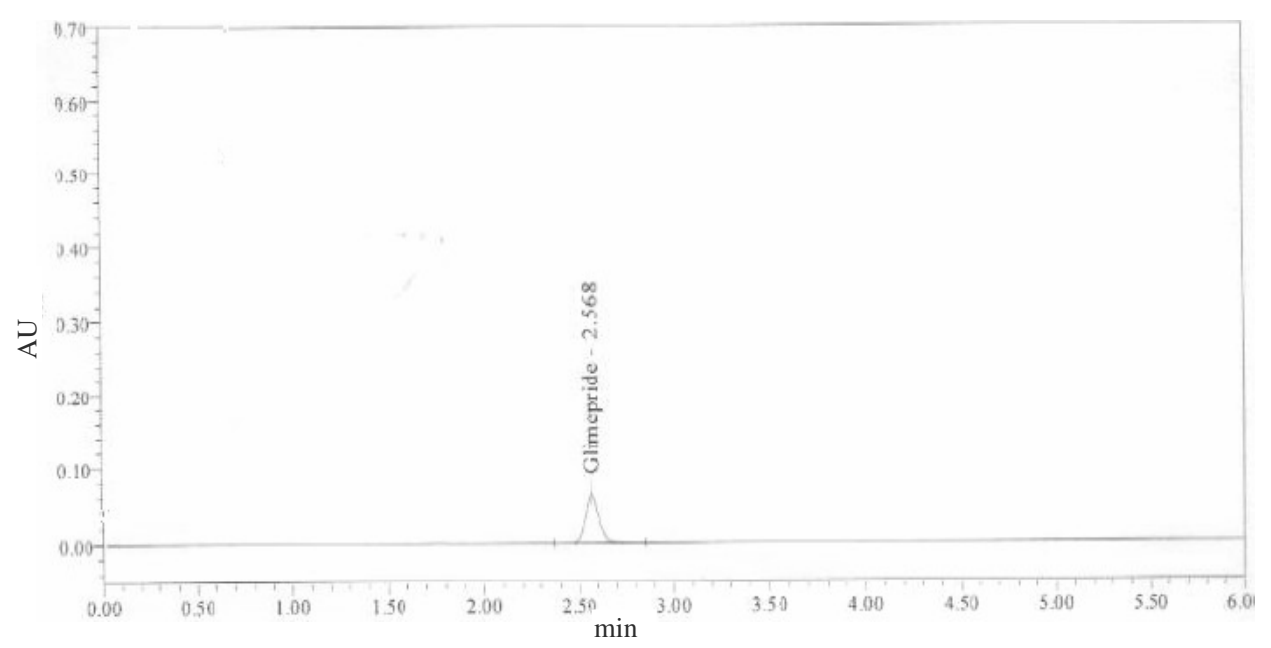

Figure 8. Specificity chromatogram of glimepride (Internal standard).

\section{System suitability}

System suitability testing is an integral part of analytical procedures. The tests are based on the concept that the equipment, electronics, analytical operations and samples to be analysed constitute an integral system that can be evaluated as such. System suitability testing is performed to ensure system performance before and during the analysis, which demonstrates that the system is operating properly and is ready to deliver results with acceptable accuracy and precision. System suitability tests were performed as per the USP 31 to confirm the suitability and reproducibility of the system. The test was carried out by injecting $10 \mu \mathrm{L}$ six replicate injections of standard solutions of cinitapride and glimepride as internal standard of 30.0 and $50.00 \mu \mathrm{g} \mathrm{mL}^{-1}$ respectively. The relative standard deviation values were found to be satisfactory and meeting the requirements of USP 31 . Theoretical plates, resolution, tailing factor were determined and are presented in Table 6.

Table 6. Theoretical plates, resolution, tailing factor.

\begin{tabular}{ccccc}
\hline \multirow{2}{*}{ Replicate $\mathrm{n}=6$} & \multirow{2}{*}{ Area ratio } & \multicolumn{2}{c}{ Tailing factor } & \multirow{2}{*}{ Resolution } \\
\cline { 3 - 4 } & & Cinitapride & Glimepride & \\
\hline Mean & 2.122 & 1.08 & 1.08 & 6.44 \\
\% RSD & 0.83 & & & \\
\hline
\end{tabular}

\section{Conclusion}

A stability indicating reversed phase liquid chromatograph was developed for determination of Cinitapride during stability testing as per ICH recommended stress studies. Composition of mobile phase as well $\mathrm{pH}$ value of mobile phase was played important role in method development. Several mobile phases such as phosphate buffer-methanol/acetonitrile in different ratios were tried at different $\mathrm{pH}$ value. It was observed that cinitapride was less retained in acidic $\mathrm{pH}$ valve, while glimepride was more retained in acidic $\mathrm{pH}$ value. Finally, good peak shape and good resolution between Cinitapride and Glimepride were observed using the mobile phase mentioned in chromatographic conditions. Forced degradation studies revealed that possible degradation products do not interfere with the determination of cinitapride. The developed method after being completely validated showed satisfactory data for all the method validation parameters. The method was found to be specific. The low 
values of relative standard deviation for method precision suggested that the method is precise. Linearity evaluated for the analyte peak showed a good linear response over a wide range of concentration. The proposed reversed phase liquid chromatographic method was validated over the linearity, precision, accuracy and specificity, proved to be convenient and effective for the determination of cinitapride during stability testing of the active substances. Moreover, the lower solvent consumption along with the short analytical run time of $6.0 \mathrm{~min}$ leads to cost effective chromatographic method.

\section{References}

1. Gonzalez M I, Gonzalez P C and Blanco Lopez M A, Analytica Chimica Acta, 1998, 368(1), 175-181.

2. Shikha M.N. Roy, Santosh M.Yetal ,Sangita V.Chavan, Varad R. Pradhan and Santosh Joshi, E-Journal of Chemistry, 2008, 5(3),453-460.

3. Alarcon de la Lastra1 C, La Casa1 C, Martin1 M J and Motilva1 V, Inflamm Res., 1998, 47(3),131-136.

4. Massingham R, Bou J and Roberts D J, J Auton Pharmacol., 1985, 5, 41-53.

5. Ames.Tonini M, De Ponti F, Di Nucci A and Crema F, Aliment Pharmacol Ther., 1999, 13,1585-1591.

6. Totah R A and Rettie A E, Clin Pharmacol Ther., 2005, 77, 341-352.

7. Snyder L R, Kirland J J and Glajch J L, Practical HPLC method development, $2^{\text {nd }}$ Edn., John Wiley \& Sons, Inc., U.S.A., 1997.

8. ICH, Validation of Analytical Procedures: Methodology, International Conference on Harmonization, IFPMA, Geneva, 1996.

9. ICH, Stability Testing of New Drug Substances and Products, International Conference on Harmonization, IFPMA, Geneva, 2003.

10. Singh S S and Bakshi M, Pharm Technol., 2000, 1,1-14.

11. Singh S S and Bakshi M, J Pharm Biom Anal., 2002, 28, 1011-1040.

12. ICH, Stability Testing: Photostability Testing of New Drug Substances and Products, International Conference on Harmonization, IFPMA, Geneva, 1996.

13. Bakshi and Singh S S, J Pharm Biom Anal., 2004, 36, 769-775. 


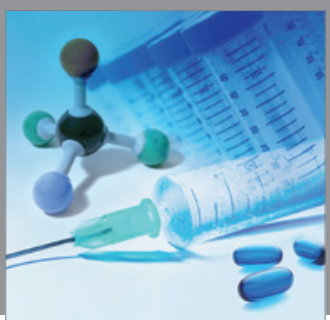

International Journal of

Medicinal Chemistry

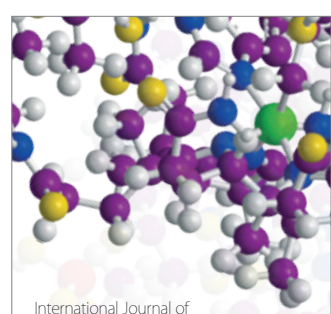

Carbohydrate Chemistry

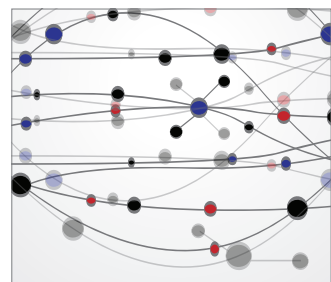

The Scientific World Journal
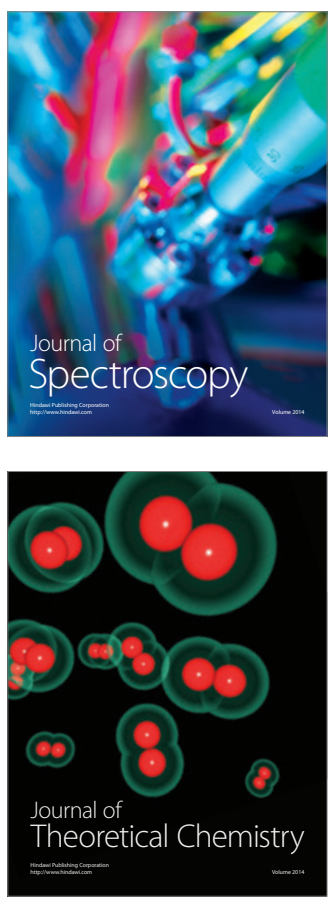
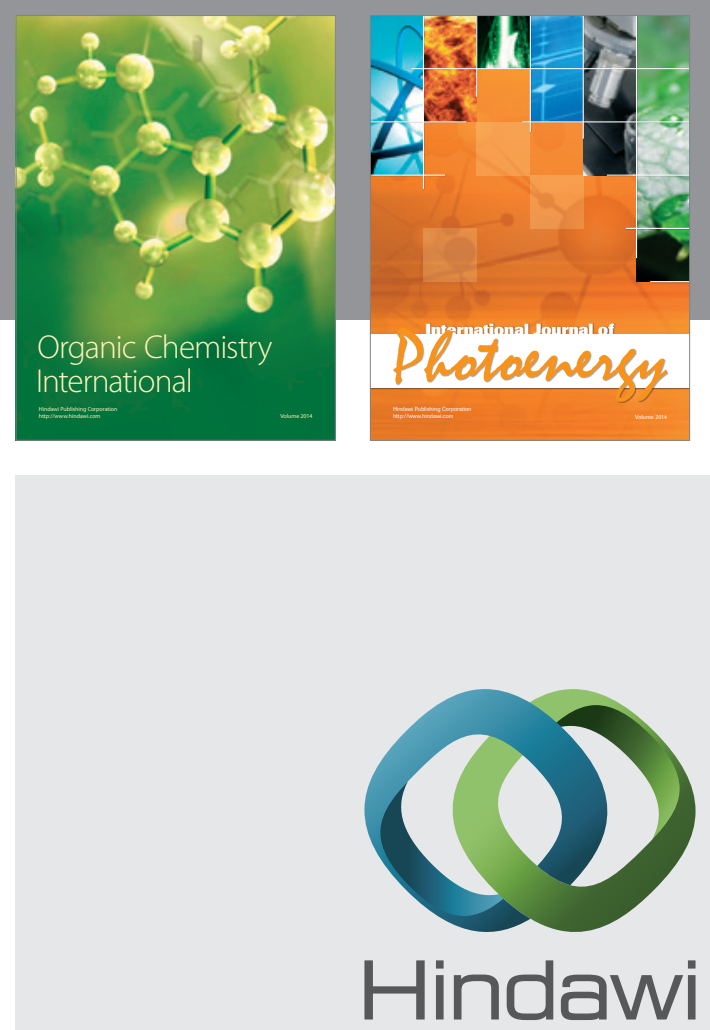

Submit your manuscripts at

http://www.hindawi.com
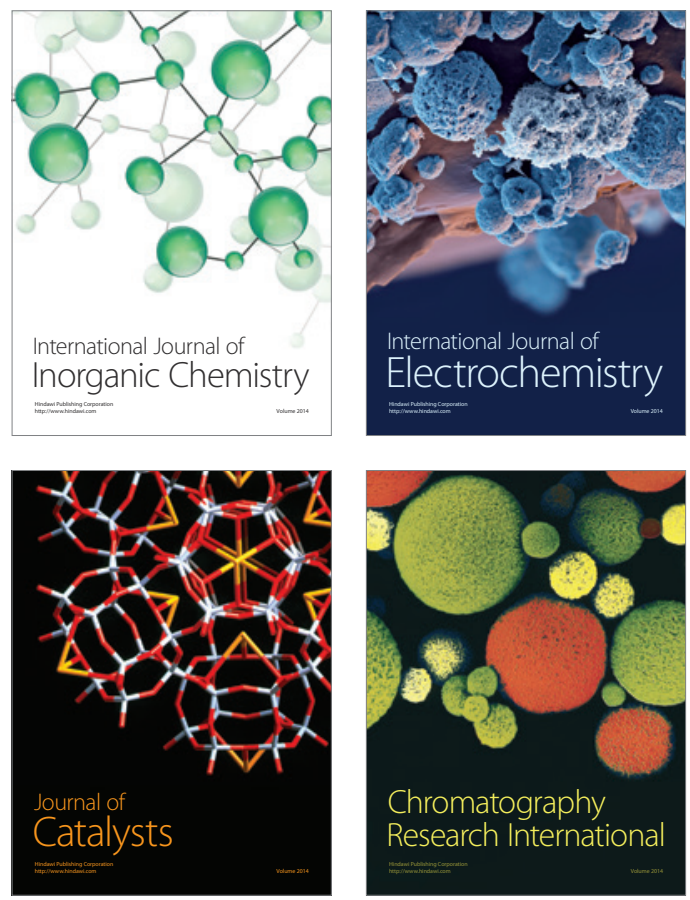
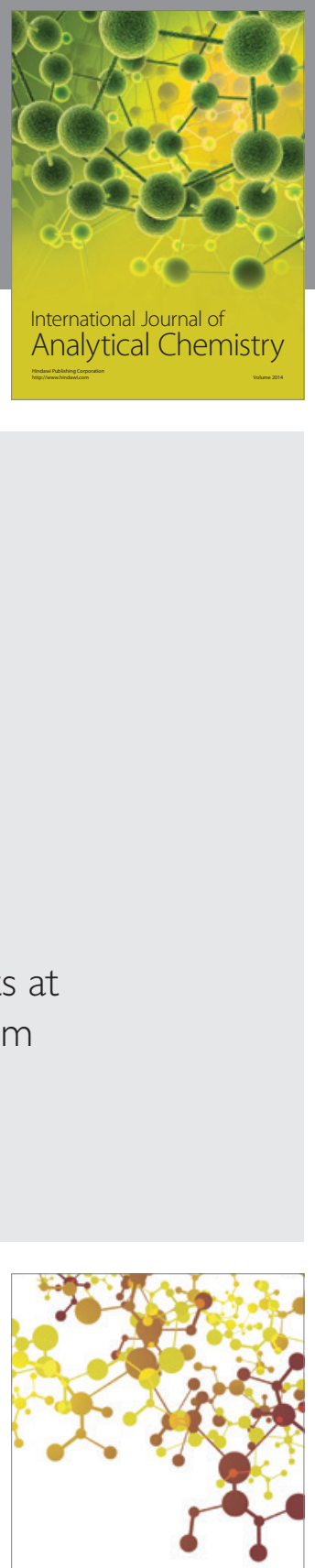

Journal of

Applied Chemistry
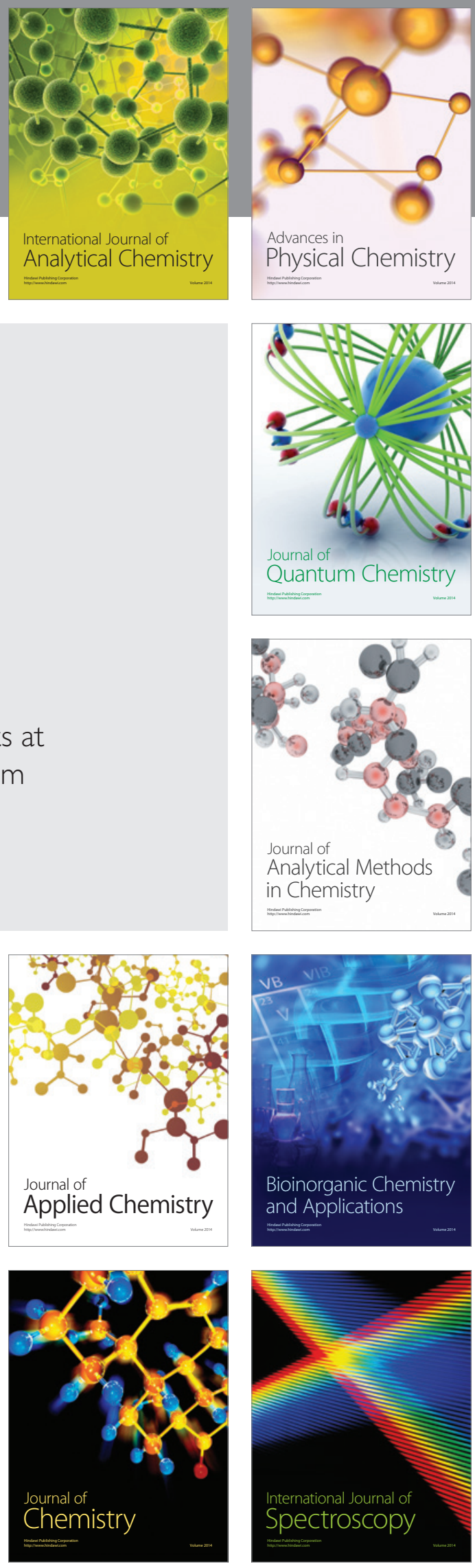